Journal of Global Mobility, Volume 4, Issue 3, 2016, pp. 276-299

DOI:10.1108/JGM-05-2016-0021

\title{
The Correspondence Model of Cross-Cultural Adjustment: Exploring Exchange \\ Relationships
}

\section{Authors: Arno Haslberger and Michael Dickmann}

\section{Abstract}

\section{Purpose:}

There has been tremendous interest in the field of cultural adjustment in the past decades. The work of Black and his colleagues has inspired many researchers. However, critics have pointed out that their original conceptualization has limitations; most of the insights building on their model have probably been harvested. Therefore, it is appropriate to investigate alternative ways at understanding the challenges in international assignments. In this paper we outline a model rooted in person-environment (P-E) fit theory. We follow Dawis and Lofquist's Theory of Work Adjustment (TWA), which has had only a small influence on expatriate research to date.

\section{Design/Methodology/Approach:}

The paper develops a correspondence model of cross-cultural adjustment and explores the diverse factors and their interactions in-depth. The satisfaction of individual needs and corresponding environmental supplies (macro, micro and organizational factors) as well as the satisfactoriness of individual abilities and corresponding environmental requirements (macro, micro and organizational) is outlined. 


\section{Findings:}

Based on the literature and the model a large number of hypotheses in relation to cross-cultural adjustment are proposed which allow new avenues in adjustment research.

Originality/Value:

The contribution of this paper is to propose a model that addresses the main criticisms to the adjustment conceptualization of Black and his colleagues. 


\section{The Correspondence Model of Cross-Cultural Adjustment: Exploring Exchange Relationships}

\section{Introduction}

The prevalent model for the investigation of expatriate adjustment in business settings has been around for more than two decades (Black, Mendenhall, \& Oddou, 1991). It has guided numerous studies (Bhaskar-Shrinivas, Harrison, Shaffer, \& Luk, 2005; Hechanova, Beehr, \& Christiansen, 2003) which have contributed substantially to our understanding of adjustment. Yet, it has been criticized for shortcomings for more than two decades (Brewster, 1993) and authors have argued that using their conceptualization is unlikely to strongly advance our insights further (Haslberger, Brewster, \& Hippler, 2013). Therefore, it is appropriate, even necessary, to investigate alternative ways at understanding the challenges in international assignments. In this paper we develop the outlines of a model rooted in the tradition of person-environment (P-E) theory. We follow Dawis and Lofquist's (1984) Theory of Work Adjustment (TWA), which has had only a small influence on expatriate research to date (e.g., Ady, 1995; Breiden, Mohr, \& Mirza, 2006; Haslberger et al., 2013; Newman, Bhatt, \& Gutteridge, 1978). Although not specifically mentioning P-E fit theory as their backdrop other authors also build their argument around the correspondence of demands and resources (cf. Lazarova, Westman, \& Shaffer, 2010).

The manuscript outlines first some of the key criticism to the conceptualization of cross-cultural adjustment by Black and his colleagues. Second, we develop a new model of cross-cultural adjustment rooted in the theoretical perspective of P-E fit and utilizing Dawis and Lofquist's TWA. Our conceptualization strives to overcome the key criticisms levied at Black et al's work 
and allows to explore an individual's self-evaluation of adjustment and to contrast it with an evaluation by host-country individuals. Because our model is based on correspondence ideas, it accommodates an assessment of 'requisite' levels of adjustment from the perspective of the organization. Based on our conceptualization we develop a large number of hypotheses before concluding with an overall outline of the model and its theoretical contributions.

\section{Reflections on the Black et al Model of Expatriate Adjustment}

Black's work from 1988 in which he identifies three adjustment dimensions (interactions in the workplace, with host nationals and general environment) and its further development with colleagues (e.g. Black et al., 1991; Black \& Stephens, 1989) has without doubt had a substantial impact amongst academics and practitioners and advanced our insights. The conceptualization and operationalization became the instrument of choice for investigations into expatriate adjustment for the next two decades (among recent examples are: Benson \& Pattie, 2009; Chen,

2010; Kim \& Slocum, 2008; Okpara \& Kabongo, 2011; Osman-Gani \& Rockstuhl, 2009; Peltokorpi, 2008; Puck, Kittler, \& Wright, 2008; Selmer, 2006b, 2006a; Siers, 2007; Takeuchi, Shay, \& Li, 2008).

Nevertheless, Black et al's conceptualization of expatriate adjustment has attracted substantial criticism (Harrison, Shaffer, \& Bhaskar-Shrinivas, 2004; Thomas \& Lazarova, 2006). Among the key points are the following: First, the three facets of adjustment, based on a study with merely 67 responses, are empirically but not theoretically developed (Hippler, 2000; Stahl \& Caligiuri, 2005). One consequence is that the facets are loosely defined and not mutually exclusive - they overlap in practice (Suutari \& Brewster, 1999). In addition, the Black et al approach means that 
the conceptualization is not collectively exhaustive and may exclude other facets of adjustment (Thomas \& Lazarova, 2006). Second, the measures are one-dimensional and specify a degree of adjustment or non-adjustment, which is linked to the degree of psychological comfort and subjective well-being. Haslberger, Brewster and Hippler (2013) make a convincing case to measure adjustment using discrete behavioral, affective and cognitive dimensions. Third, the Black et al model underspecifies interactions and dynamic developments in the process of adjustment. To be able to incorporate dynamics individual, situational and broader context factors need to be factored in as mutual needs and demands (of the individual and the host environment) are not independent from each other (Brammer \& Abrego, 1981).

From the above it has become clear that a new conceptualization can benefit research in the expatriate adjustment area. Our work takes up this challenge and outlines a new, advanced adjustment model below.

\section{Model Outline}

P-E fit models have made an important contribution to behavioral studies (Edwards, 2008).

TWA's creators have applied their approach in other settings, which indicates that it may also be well-suited for the analysis of international assignments (Lofquist \& Dawis, 1991). TWA states that individual and environment are in a continued interaction as long as they meet to some extent each other's requirements. An indicator of adjustment in TWA is tenure in a job. We will include tenure in our discussion so as to not deviate too far from TWA but are fully aware that other or additional indicators of adjustment are necessary. In expatriate assignments tenure or length of stay is but one indicator of adjustment and a potentially problematic one (Harzing, 
1995; Harzing \& Christensen, 2004). The term “correspondence" expresses the degree to which (1) environmental supplies meet individual needs (satisfaction), and (2) individual capabilities meet environmental requirements (satisfactoriness) (Dawis \& Lofquist, 1984). The drawing in Figure 1 is based on TWA. ${ }^{1}$ It modifies the theory by distinguishing different environments, the organization and the host society at large, to reflect the fact that expatriates contrary to domestic job changers have to adjust to both. In a domestic setting it is presumed that in the non-work sphere the available environmental supplies meet the individual's needs and that the environmental requirements are met by individual abilities (albeit to differing degrees for different individuals). Strictly speaking, this may not entirely be true since within a nation there can be large regional differences. In cross-national moves by expatriates these differences may be huge and cannot be ignored. Hence we extend the TWA model accordingly. ${ }^{2}$

\section{Insert Figure 1 here}

The discussion of the model proceeds in two iterations. First, we discuss the top half of Figure 1, which captures the internally assessed side of the adjustment process. We start with the individual's needs and follow with the supplies available in the micro/macro and the organizational environment. In a second iteration, we discuss the bottom half of Figure 1 that

\footnotetext{
${ }^{1}$ The drawing incorporates ideas from other sources, which will be identified in the discussion of the model and its implications.

${ }^{2}$ A recent application of TWA to expatriates also includes the correspondence of an expatriate's abilities, e.g. to adjust, to his or her needs, e.g. to be adjusted (Haslberger, Brewster, \& Hippler, 2013). We acknowledge the relevance of the authors' extension yet exclude it here to avoid overloading an already complex model. Future research should try to incorporate that extension as well.
} 
deals with externally assessed side. Here environmental requirements have to be met by the expatriate's abilities to make the individual satisfactory in the eyes of the environment. As long as there is a minimum level of satisfaction and satisfactoriness the interaction continues and the adjustment process proceeds. The discussion shows the relative nature of adjustment as the extents of satisfaction and satisfactoriness result from the dynamic interaction of needs and supplies as well as requirements and abilities respectively. A low level of needs met by a low level of supplies will result in the same overall level of satisfaction as a high level of needs met by a high level of supplies. The same is true for satisfactoriness. The focus on this dynamic balance constitutes a unique contribution of the P-E fit model and brings it closer to the actual reality of the expatriate experience than previous more linear models.

Based on the TWA correspondence between the various demands and resources will lead to positive outcomes such as satisfaction and satisfactoriness of the individual, which is likely to result in adjustment. Thus, our model includes four elements relevant for the adjustment of expatriates: (1) their satisfaction with and (2) satisfactoriness in the work environment, and (3) their satisfaction with and (4) satisfactoriness in the general environment. These relationships are based on a range of underlying assumptions, which are implicit in our model. They stem from a basic application of TWA to adjustment - for comprehensiveness we have listed these in Appendix 1.

It is important to point to some possible disparities between cross-cultural adjustment and correspondence-related adjustment. The purpose of the assignment, as discussed later, may stipulate that the expatriate adjusts very little to the host culture. In such a case, the meeting of 
organizational requirements would coincide with relatively poor cross-cultural adjustment. In most other instances, the distinction of cross-cultural and correspondence-related adjustment will be unnecessary because the organization either supports cross-cultural adjustment or, at least, does not oppose it.

There are many different types of global experiences and international travel. For instance, Baruch et al. (2013) distinguish 20 forms of global careers. Our model explores how individual and environmental demands and supplies correspond with a focus on assigned expatriates. But the applicability of the model is not restricted to them. The adjustment of self-initiated expatriates could be explored with our model as well. With appropriate changes to the variables included, the model can serve in the investigation of yet other types of global assignments.

Every model of expatriate adjustment struggles with the question of which of the many possible variables to include. Lazarova et al. (2010), for example, provide a non-exhaustive list of over 60 most commonly used variables. Our selection has a threefold purpose: first, to be parsimonious without being simplistic, second, to root our research in prior literature and thus provide a check for the validity of results and third, to introduce a small number of new variables that have received scant attention so far "to make the mesh ever finer and finer" (Popper, 2002: 38). The P-E fit concept of correspondence between demands (individual needs and environmental requirements) and resources (individual abilities and environmental supplies) guides us in variable selection: demand and resource variables have to be matched. The table below gives an overview of the model variables included. The discussion following it will explain them. 


\section{Insert Figure 2 here}

\section{Discussion of Model Variables}

The TWA model distinguishes two types of correspondence between demands and resources. First, we will focus on the individual's satisfaction in the environment. Every expatriate has a set of needs that the societal and organizational environments have to meet. If they are not met, the expatriate's adjustment will suffer and the tenure in the host country may be shortened. Second, we will attend to the satisfactoriness of the individual to the environment. Every expatriate has to meet certain expectations of the host society and of the employing organization. A shortfall in the former will render the expatriate unadjusted in the eyes of the hosts that may impact tenure negatively; a shortfall in the latter will have a more direct impact on tenure, as the expatriate will be regarded as failing to meet performance targets. If an expatriate's abilities do not meet societal and/or organizational requirements adjustment will be low.

SATISFACTION IN THE ENVIRONMENT (INTERNALLY EVALUATED ADJUSTMENT)

Satisfaction is an important construct in social science in general and in organizational behavior in specific (cf. Greenberg, 2011; McShane \& Von Glinow, 2010). It features in models of the employment process such as employee turnover (Lee \& Mitchell, 1994; Mobley, 1982) and work-role transitions (Dawis \& Lofquist, 1984; Nicholson, 1984). In expatriate adjustment it is usually treated as an outcome (Bhaskar-Shrinivas et al., 2005; Hechanova et al., 2003). The dynamic nature of the adjustment process (Haslberger, 2005; Mendenhall \& Macomber, 1997) means that it may equally well feature as an antecedent, i.e. the level of adjustment can influence 
variables that are normally treated as antecedents to adjustment such as language skills or selfefficacy. Our model allows us to incorporate some of the dynamic aspects of adjustment.

\section{Individual demands (needs) to be met by the environment}

The fulfillment of individual needs through environmental supplies will aid adjustment. The expatriate literature does not include much on the needs of expatriates. However, it is clear from Nicholson's (1984) Theory of Work Role Transitions that the need for feedback and the need for control are adjustment-relevant variables. They relate to the motivational orientation of the person in transition. We distinguish here a general need for feedback and for control and workrelated needs for both. The general need for feedback includes the desire to get information from members of the host society about one's language skills and cultural performance, for example. The general need for control refers to the expatriate's desire to get things done and to live without undue interference by the hosts. The work-related needs are similar with a focus on the job and the organizational environment.

The four-drives theory of motivation includes the drive to bond besides the drives to acquire, defend, and learn (Lawrence \& Nohria, 2002). Drives are related to individual needs because these are manifestations of drives transformed by past experience, social norms and personal background (McShane \& Von Glinow, 2010). Needs related to the drive to bond would be the desire to belong, the desire to be accepted by members of the host culture and the desire to interact with them. Berry, Kim and Boski (1988: 66) capture some of this as the "value to maintain relationships with other groups". Needs related to the drive to bond operate in the workplace, too, and affect the development of networks in the office. Work-based local networks 
are important to understand new demands on the expatriate (Huang, Chi, \& Lawler, 2005).

Work colleagues can help expatriates to 'decipher' the host country culture (Vance, Vaiman, \& Andersen, 2009) with a range of positive bonding experiences (Dickmann \& Baruch, 2011). Coworkers can, therefore, facilitate the expatriate's adjustment and work performance (Toh \& DeNisi, 2007). ${ }^{3}$

The surge of religion-related political issues on the world stage as well as the increased attention workplace spirituality (Giacalone \& Jurkiewicz, 2003; Haslberger, 2011; Lips-Wiersma, 2002; Pfeffer, 2003) has received over the last decade suggests that the need to be able to pursue one's spiritual or religious goals may be relevant in expatriate assignments, too (Oku, 2007). Therefore, we include the related need as novel and as yet under-researched variable in expatriate studies. Giacalone and Jurkiewicz' (2003: 13) definition of “workplace spirituality" includes the central feature of spirituality in general, which is a "sense of being connected to others in a way that provides feelings of completeness and joy." This suggests that spirituality may be regarded as an element of adjustment. Therefore, to be able to pursue one's spiritual or religious goals abroad will enhance expatriate adjustment.

\footnotetext{
${ }^{3}$ We would like to acknowledge the observation and related reference of an anonymous reviewer that there are 'alternate drives for interaction' besides the drive to bond. (See: Ditchburn, G. \& Brook, E. R. 2015. Cross-cultural adjustment and fundamental interpersonal relations orientation behaviour (FIRO-B). Journal of Global Mobility, 3(4): 336-349.)
} 


\section{Micro/macro-environmental resources (supplies) to fill individual needs}

The environment provides certain supplies that aid individual adjustment. Later we show by way of some examples how a matching of each of the demands with each of the supplies guides the development of hypotheses.

Countries vary in their appreciation of ethnic diversity and how much they trust people of other nationalities (Anonymous, 2009). This will influence the receptivity different countries show for expatriates. Kim (2001: 148) defines in her communication-focused theory of cross-cultural adjustment the receptivity of the host environment as "the natives' openness toward strangers and willingness to accommodate strangers with opportunities to participate in the local social communication processes." We suggest that it also includes the openness of the host society to religions other than the one of the mainstream. Receptivity is a two-fold variable: first, in the sense implied by Kim (2001) different cultures vary in their receptivity to strangers, and second, a single culture does not show the same level of receptivity to all strangers. Rather, receptivity may vary by country of origin of the stranger whereas a person from a poor country, say Bangladesh, and an otherwise matched person from a rich country, say Canada, may find different levels of openness and willingness to include them. Countries' reputations vary considerably (Anonymous, 2012). Similarly, a Coptic Christian and a Muslim in spite of being from the same foreign country may experience differing host receptivity in, say, a strongly Catholic country.

External supplies facilitating individual adjustment include social networks. Social networks can facilitate expatriate life by lending social support or can make it more difficult by adding strain. 
Wang (2002) regards social networks as factors that moderate the influence of antecedents on outcome variables. She focuses exclusively on the supportive function of networks, which includes emotional support, instrumental support, informational, and feedback support. Emotional support helps expatriates in overcoming frustrations. Instrumental support helps "them to obtain what they need and to carry out their assignment" (Wang, 2002: 326). Informational and feedback support both provide information: the first one more of a general and external nature about the culture and environment, which reduces uncertainty, and the second one of an evaluative and personal nature. Networks have the following structural characteristics: size, diversity, density, closeness, and frequency of contact. Size refers to the number of persons in the network. Diversity indicates the social heterogeneity of the network including local or expatriate contacts. Density is "the ratio of the number of actual social ties to the number of possible ties in the network" (Wang, 2002: 328). Network diversity and density are related such that a more heterogeneous network is normally less dense. Wang (2002) argues that this is not necessarily true for expatriate networks, which can be very high in density and, at the same time, high in diversity. This may be the case when people from many different countries including local nationals are substantially involved in expatriate networks. While density is a network-level variable, closeness "describes the dyadic relationship between the expatriate and each partner ... [and] is defined by mutual trust and attraction" (Wang, 2002: 329). Frequency defines how often the expatriate meets with network partners in a given time span. We regard strong social networks as an adjustment-facilitating factor in addition to Wang's proposed moderating effects. Expatriate networks that exclude local nationals may turn into "environmental bubbles" (Cohen, 
1977) that may increase individual well-being but not necessarily adjustment to the host culture (Brewster \& Pickard, 1994).

National cultures vary in their communication patterns with respect to the messages transported within the words or derived from the context as well as their associated directness (Hall, 1976). The willingness to provide (open) feedback varies between cultural areas and its effects have been described by writers such as Lewis (2006) or Trompenaars and Hampton-Turner (1997). Distinct preferences for direct feedback have been described as a 'Hamburger Model' by Dickmann and Baruch (2011) in which straightforward and direct feedback was identified in countries such as Germany and the willingness to engage in this direct style of communication was relatively low in other countries. In Japan, for example, communication is more circumspect, high in context and low in direct expression (Hall, 1976). Lack of feedback to the expatriate that is comprehensible or culturally unobjectionable because it is not direct enough or too direct decreases understanding. If, however, expatriates get feedback that they can understand and interpret correctly their chances of adjustment improve.

Discretion supports adjustment (Harris, Brewster, \& Sparrow, 2004). Discretion that is granted to strangers by the host environment is a variable that is the flip side of conformity pressure felt by strangers. While discretion is a resource, conformity pressure is a requirement that will be discussed below. Nicholson (1984) includes role discretion in his Theory of Work Role Transitions. In the work sphere it refers to the employee's scope in altering various components of the job. Low discretion allows little opportunity to change aspects of the job, while high discretion enables the jobholder to alter the role. Analogously, by giving discretion to expatriates 
the host society allows them to deviate from or ignore certain norms that are more mandatory for members of the host society.

Various authors have identified motives to move to another country unrelated to work. A thirst for adventure or travel (Doherty, Dickmann, \& Mills, 2011), location-specific positive factors, including arts and other extra-curricular activities (Dickmann, 2012) as well as climate (Hippler, 2009) play a role. In contrast, the host location may also exhibit unattractive facets, including some from the previous list such as climate. ${ }^{4}$ By going abroad, expatriates may also be unable to follow some cherished recreational activities. Perhaps their favorite sport is uncommon in the host country or a particular craft is not practiced there. Expatriates' substitution capacity varies and hence their demands on related environmental resources. As an additional environmental factor, security considerations can be relevant for foreign assignees. In their study of expatriation drivers in several dozen multinational organizations, Dickmann et al. (2008) found that the importance of security issues was either very high or very low for individuals' motivation to go and work abroad. The authors speculate that once a country (or city) is regarded as dangerous then personal security considerations become highly pertinent. Other authors link security and freedom, which can be regarded as an aspect of discretion. Patterson (2013) researched drivers to take up employment for a governmental aid organization in fragile environments such as Afghanistan, Pakistan, Sudan or Yemen. Security concerns impacted on the expatriates' ability

\footnotetext{
${ }^{4}$ We discuss the "physical" characteristics under the heading of supplies but they may equally well be listed under demands depending on their actual expression.
} 
to move around freely, to see the work on the ground, develop their skills or develop good relationships with locals. Concerns for security and freedom of movement or expression are likely to negatively impact adjustment. In addition to the broad environmental resources there are also organizational supplies that can help to fulfill individual needs.

Organizational resources (supplies) to fill individual needs

A well-designed job may constitute a resource for the expatriate. It can create an island of familiarity and stability in a sea of change. The Job Characteristics model (Hackman \& Oldham, $1975,1976)$ suggests that job design in conjunction with personal characteristics have an impact on motivation and job satisfaction. The model is well-established and is regarded as having good validity (Fried \& Ferris, 1987; Miner, 2005), although its creators caution that the phenomenon "job" has changed sufficiently to "have profound implications for job design research" (Oldham \& Hackman, 2010: 466). The exact nature of these implications is yet unclear. Based on what we know so far, job characteristics also have an impact on expatriate work adjustment (BhaskarShrinivas et al., 2005). The Job Characteristics model includes skill variety, task identity, task significance, autonomy, and feedback from the job. The first three relate to the meaningfulness of the job. All professional expatriate jobs tend to be relatively high in skill variety, task identity, and task significance so that we do not expect sufficient variation to justify inclusion in the present model. We will focus on autonomy and feedback because we expect them to vary more from one professional expatriate job to another. In addition, recent research on job characteristics also incorporates job complexity (Judge, Bono, \& Locke, 2000). In expatriate research role clarity, discretion, novelty, and conflict have featured prominently (Bhaskar-Shrinivas et al., 
2005). Job discretion includes a hierarchical dimension in that jobs higher in the hierarchy normally have higher discretion. Job characteristics may constitute resources such as high clarity, but they could equally feature as a demand. Nicholson (1984), for example, calls role discretion and role novelty requirements. Similarly, a job high in complexity demands more of the jobholder than a low-complexity job. We will include the various job characteristics here as organizational supplies. To play the role of supplies, the following needs to be high: autonomy, feedback, role clarity, and role discretion; the remainder need to be low, i.e. job complexity, role novelty, and role conflict to support adjustment.

Expatriates will experience receptivity and conformity pressure in the workplace in the same fashion as in their general environment. The receptivity of local employees and their identification of expatriates as in-group or out-group affect work adjustment (Toh \& DeNisi, 2003 , 2005, 2007). This will be influenced by the relative status of the home and host cultures as discussed earlier. As an organization-specific variation, it is to be expected that expatriates from the HQ country will enjoy higher receptivity and less conformity pressure than people from other countries. The reasons for this are multifaceted and complex. First, the organizational culture in the host location may be somewhat similar to the one at HQ and thus influenced by the HQ country culture. This effect will be stronger for strong organizational cultures than for weak ones. Second, expatriates from HQ may be perceived to or actually be better connected to important decision makers than third-country nationals (TCNs), which would make it more desirable to be close to expatriates from HQ than those from other countries (Dickmann \& Baruch, 2011; Harris et al., 2004). 
Networks in the organizational environment have, in principle, the same effects as networks in the host environment at large. Their main area of influence will be in the work environment just as non-work networks will operate mostly outside of work. This does not, though, preclude positive or negative spillover effects comparable to those discussed in the literature on the workfamily interface (Edwards \& Rothbard, 2000).

There is a wide array of organizational support practices to facilitate the move of individuals (and their families) to a host country and the adjustment to a new cultural context. Textbooks are full of recommendations how organizations can provide administrative help to expatriates (Dowling, Festing, \& Engle, 2008). Authors such as Briscoe et al. (2009) or Osland et al. (2006) suggest pre-departure training and post-arrival development to explore cultural differences. Mentoring and coaching - especially by an experienced local - address individuals' needs to make sense of their environment. They are resources provided by the organization likely to be effective in aiding both self-initiated and assigned expatriates to adjust (Andresen, $\mathrm{Al}$ Ariss, \& Walther, 2012; Vaiman \& Haslberger, 2013)

The foregoing discussion of needs- and supplies-related variables is based on the underlying hypothesis that the higher the fulfillment of needs (i.e. the higher the correspondence of needs and supplies), the higher will be an individual's adjustment. Based on our in-depth exploration of the individual demands and environmental resources we can develop a large array of hypotheses. We will only present a few with several more listed in Appendix 2. They serve as examples without claiming to be comprehensive: 


\section{MACRO/MICRO ENVIRONMENT}

- The expatriate's satisfaction with the environment increases to the extent that needs related to the drive to bond are met by receptivity for strangers.

- The expatriate's satisfaction with the environment increases to the extent that needs related to pursue one's religion are met by receptivity for strangers.

- The expatriate's satisfaction with the environment increases to the extent that needs for general feedback, for general control, and needs related to the drive to bond are met by the size (in terms of sheer numbers) of non-work support systems.

\section{ORGANIZATION}

- The expatriate's satisfaction with the organization increases to the extent that the need for feedback is met by feedback from the job and by role clarity.

- The expatriate's satisfaction with the organization increases to the extent that the need for control is met by autonomy/discretion and by role clarity.

- The expatriate's satisfaction with the organization increases to the extent that the need for feedback and needs related to the drive to bond are met by receptivity of host employees.

Having outlined the individual demands to be met by environmental and organizational resources we are now turning our attention to demands by the broader and corporate context levied on the individual.

\section{SATISFACTORINESS OF PERSON (EXTERNALLY EVALUATED ADJUSTMENT)}

Expatriate adjustment requires an individual's satisfactoriness in the eyes of the outside world. This means that the external environment, i.e. the host society and the host organization, senses 
that the expatriate meets respective minimum requirements. Absent that each part of the environment signals directly or subtly to the expatriate his or her inadequacy and perceived lack of adjustment.

\section{Macro/micro-environmental demands (requirements) to be met by the individual}

Every culture has rules, norms and behavioral expectations for its members and guests. Most of these are not absolute. Children, for example, get dispensation from conforming to them depending on age. Foreigners may be granted exceptions, e.g. the "gaijin attitude" towards women identified in some Asian countries (Adler, 1987). Kim (2001: 152) defines conformity pressure as "conscious or unconscious pressure on strangers to change their original patterns of behavior and adopt those of the host culture." Conformity pressure like receptivity is related to countries' appreciation of ethnic diversity and how much they trust people of other nationalities (Anonymous, 2009). The less people trust other nationalities and the less they appreciate ethnic diversity, the more they will insist on expatriates to conform to local standards. The pressure exerted in a given country will vary by the foreigner's country of origin. Research in Luxembourg showed that expatriates from developing countries faced more negative attitudes (Langinier, 2012), which would result in higher conformity pressure on them. Besides the status of the home culture, expectations will vary based on the socio-economic status of the foreigner. The point systems some countries have for the granting of "green cards" that take into account education, profession, and wealth of applicants are an obvious sign of the impact of the socioeconomic status variable. Since these legal rules are in the public eye when they are being 
developed and evaluated, they are bound to influence the thinking of the public and hence the conformity pressure applied to different foreigners.

Any move necessarily results in unfamiliarity. Even a cross-town move requires learning the "lay of the land". While this is often trivial with regards to amenities and facilities in terms of physical characteristics, it can present a considerable novelty challenge in cross-cultural moves in terms of how to use them. This is but one element of the underlying concept of cultural novelty. Past research showed ambiguous effects, but meta-analytic evidence indicates a clear influence on adjustment (Bhaskar-Shrinivas et al., 2005). A related but different concept is cultural distance. It is the essence of cross-cultural indicators comparing countries (Hofstede, 2001; House, Hanges, Javidan, Dorfman, \& Gupta, 2004). Cultural distance has the advantage of being objective, but the disadvantage of representing an aggregate that necessarily ignores individual differences among persons of the same country in their values on the indicators. It also ignores the familiarity with another culture acquired in previous contacts such as prior assignments, which may moderate adjustment in the current assignment (Takeuchi, Tesluk, Yun, \& Lepak, 2005). Cultural novelty, on the other hand, takes into account the differences among people and their experiences. It represents a subjective perception. The beneficial effect of previous experience in the host country wears off over time (Takeuchi et al., 2005). Therefore, a location that may have been experienced as holding low novelty upon return after a couple of years because the effect of previous experience is still salient may seem high in novelty after a decade. Cultural novelty, even though it is based on subjective perception, represents an environmental challenge to adjustment that the expatriate needs to meet with his or her resources. 


\section{Organizational demands (requirements) to be met by the individual}

The purpose of the assignment defines the overall objective of the international assignment and constitutes an organizational requirement. Evans, Pucik, and Björkman (2011) distinguish demand-driven and learning-driven assignments. The latter focus on the development of the expatriate's competencies in the international arena in general or in the host country specifically. In any case, there will be a requirement to adjust and acquire new skills. Demand-driven assignments are more diverse in terms of their adjustment requirements. If the demand is corporate control, for example, too much identification with the host location and therefore adjustment to it may be undesirable (Brewster, 1993, 1995). If the demand is the creation of local ties or some other job involving extensive interaction with members of the host culture, the requirement may be to adjust fully to the new environment, including a language and cultural learning challenge.

Macro/micro-environmental requirements, by their nature, increase the adjustment challenge. Organizational requirements, on the other hand, pitch the adjustment challenge at a certain level; higher for developmental and externally or exchange-focused assignments, lower for internally focused ones, and lowest for control-focused ones.

Individual resources (abilities) to fulfill environmental requirements

Every expatriate has a unique set of abilities that constitute the resources to meet environmental requirements. The better an individual's resources correspond to environmental demands, the better he or she can adjust and the more adjusted he or she will seem to the external environment. The expatriate's personality plays an important role in the investigation of adjustment abroad 
(Aycan, 1997; Caligiuri, 2000b, 2000a; Harrison, Chadwick, \& Scales, 1996; Kumar \& Rose, 2008; Peltokorpi \& Froese, 2012; Shaffer, Harrison, Gregersen, Black, \& Ferzandi, 2006; Van Vianen, De Pater, Kristof-Brown, \& Johnson, 2004; Ward, Leong, \& Low, 2004). Expatriate personality can foster adjustment or become a hindrance. The "Big Five" personality dimensions have received considerable research attention and have shown some effects on adjustment (Aycan, 1997; Caligiuri, 2000b, 2000a; Kumar \& Rose, 2008; Shaffer et al., 2006; Ward et al., 2004). Other personality variables such as self-efficacy (Bhaskar-Shrinivas et al., 2005; Harrison et al., 1996; Nicholson \& Imaizumi, 1993), tolerance for ambiguity and locus of control (Ward, Bochner, \& Furnham, 2001), and plenty of others (Church, 1982) have been investigated over the years. Ward et al. (2001) conclude that the evidence for the influence is not overwhelming and refer to views that it may be necessary to observe the interaction of personality and situation to produce better evidence. Since the "Big Five" have shown the most useful results in various studies, we include hypotheses on them.

People vary in their willingness to live and work abroad and to be in a particular host location. Research on the drivers of assigned expatriates has shown that key motivations include career, development, financial, location, personal interest and family considerations (Dickmann et al., 2008). Our focus here is on traditional expatriates. Self-initiated expatriates have similar categories of drivers, although they are much more likely to be motivated by personal considerations such as adventure or to see the world (Doherty et al., 2011). At times companysponsored expatriates accept their assignment as a refusal would have negatively impacted their careers (Hippler, 2009; Stahl, Miller, \& Tung, 2002). A low willingness to be in the host location is likely to impact adjustment negatively because the individual will be less motivated to learn 
the local language and culture, will place low value on establishing and maintaining relationships with members of the host society (Berry et al., 1988) and will be less willing to make personal changes to facilitate adjustment.

Many host environments hold attractions that increase people's willingness to live there. But they also are bound to lack certain things that expatriates will miss. And they will have offerings that expatriates were unaware of or indifferent to before arrival. The concept of substitution capacity (Waxin, 2004) captures the ability of expatriates to replace unavailable cherished activities and other factors by those available in the host country. A typical example is sports. An avid alpine skier moving to a tropical country might find waterskiing a viable and enjoyable alternative if substitution capacity is high. In turn for a person who scores low on substitution capacity this might be unattractive and the idea of replacing one with the other rather farfetched. Waxin (2004) found that substitution capacity is positively related to adjustment.

Countries differ in the pride for their country and its achievements (Anonymous, 2009; Evans \& Kelley, 2002) and in their self-image (Anonymous, 2012). Therefore, expatriates from different cultural backgrounds will display differing levels of "cultural confidence". Of course, not all people from a particular culture identify with equal strength with their culture and have the same cultural identity. Just as countries differ in the percentage of citizens seeing themselves as country, regional or world citizens (Anonymous, 2009), individuals from a specific country differ in their particular national and cultural identity as well as in the salience and strength of the respective dimension of their identity. The latter is especially important in multi-ethnic countries. People with a strong national identity and a high level of cultural confidence will feel 
a lesser urge to adjust than those with a weaker national identity and/or lesser cultural confidence.

The ability to speak the host-country language has a major influence on the opportunities of the expatriate. This includes social contacts, the acquisition of knowledge about the host environment, getting things done, and most other aspects of life abroad. Language skills are related to cross-cultural adjustment (Bhaskar-Shrinivas et al., 2005; Shaffer, Harrison, \& Gilley, 1999; Taylor \& Napier, 1996). It appears that language skills enhance without qualification adjustment to life in general in the host society (Bhaskar-Shrinivas et al., 2005). Adjustment to work benefits from good language skills if there is an expectation for foreigners to speak the language such as in many English-speaking countries (Bhaskar-Shrinivas et al., 2005) or where the job includes many external contacts (Taylor \& Napier, 1996).

Language skills alone, of course, do not ensure good cross-cultural adjustment. They must be paired with the ability and willingness to communicate with different people. The concept of cultural intelligence (CQ) is a recent and broad attempt to capture the overall idea (Ang, van Dyne, \& Koh, 2006; Earley \& Ang, 2003; Earley \& Peterson, 2004; Thomas \& Inkson, 2004). Various studies have shown a positive effect of CQ on cross-cultural adjustment (Ang et al., 2007; Chen, Lin, \& Sawangpattanakul, 2011; Lee \& Sukoco, 2010; Templer, Tay, \& Chandrasekar, 2006), although some researchers did not find significant effects (Ward, Wilson, $\&$ Fischer, 2011). The literature on cultural intelligence (CQ) distinguishes cognitive, metacognitive, motivational and behavioral aspects (Earley \& Ang, 2003). An investigation of the Cultural Intelligence Scale (Ang et al., 2007) shows that cognitive aspects refer to country 
knowledge. In addition, meta-cognitive aspects include a somewhat abstracted awareness of the cross-cultural dimension of one's interactions and a generalized deliberate variation of interactive behavior based on cultural requirements. Meta-cognitive CQ is similar to behavioral $\mathrm{CQ}$, which is more focused on specific situations. Motivational CQ refers to the enjoyment and confidence in cross-cultural interactions. A high CQ is seen to be positive for adjustment.

The foregoing discussion of requirements- and abilities-related variables supports the following hypotheses, which again serve as examples rather than being comprehensive:

\section{MACRO/MICRO ENVIRONMENT}

- The environment's perception of expatriate satisfactoriness increases to the extent that conformity pressure is met by appropriate expatriate behaviors.

- The higher the expatriate's agreeableness / openness (from Big Five), the higher the adherence to conformity pressure.

- The higher the expatriate's willingness to be in the host location, the higher the adherence to conformity pressure.

○ The higher the expatriate's cultural intelligence, the higher the adherence to conformity pressure.

\section{ORGANIZATION}

- The organization's perception of expatriate satisfactoriness increases to the extent that its demand for adjustment is met by appropriate expatriate behaviors. 
○ The higher the expatriate's extraversion / agreeableness / openness / conscientiousness / self-efficacy, the higher the compliance with organizational demands for adjustment.

- The higher the expatriate's willingness to be in the host location, the higher the compliance with organizational demands for adjustment.

\section{Conclusions}

There has been tremendous interest in the field of cultural adjustment in the last decades with the work of Black and his colleagues inspiring many researchers to investigate the area. Black et al.'s original conceptualization (Black et al., 1991) has encountered a variety of criticism over time (Brewster, 1993; Harrison et al., 2004; Haslberger \& Brewster, 2009; Hippler, 2000; Stahl \& Caligiuri, 2005; Thomas \& Lazarova, 2006). We believe that the field benefits from a P-E fit model that builds on prior adjustment research and provides guidance for further studies.

Every environment imposes demands on individuals who need to respond to those demands drawing on their abilities in order to show adequate behaviors. These requirements can originate at the macro- or the micro-social level (Haslberger, 2008) but also in their work environment (Black et al., 1991). At the same time, individuals have needs and personal as well as professional aspirations related to their foreign work (Dickmann et al., 2008; Hippler, 2009; Stahl et al., 2002). They are often proactively seeking to live abroad and pursue their own agendas (Doherty et al., 2011; Richardson \& Mallon, 2005; Tharenou \& Caulfield, 2010).

Our discussion of expatriate adjustment ins based in P-E fit theory as advanced by Dawis and Lofquist (1984). P-E fit theory contains two central propositions that can be stated as follows for 
expatriate adjustment. First, the more the individual's abilities correspond with environmental requirements, the higher the satisfactoriness of the expatriate in the eyes of environmental actors. Second, the more environmental supplies correspond with the individual's needs, the higher the satisfaction of the expatriate in the environment. Expanding on these ideas allowed us to develop correspondence model of cross-cultural adjustment, a detailed version of which is depicted in Figure 3.

\section{Insert Figure 3 here}

Our model represents a theoretical contribution to the field of cross-cultural adjustment research. It responds to the call for the development of alternative ways to depict and explore crosscultural adjustment that go beyond the well-trodden path following Black and his colleagues (Suutari \& Brewster, 1999; Thomas \& Lazarova, 2006). More specifically, it addresses the limitations of the Black et al conceptualization outlined above. Most importantly, our model has much stronger roots in theory and defines more clearly the manifold facets and elements of expatriate adjustment (Hippler, 2000; Stahl \& Caligiuri, 2005). In addition, its outcomes can be operationalized and assessed using behavioral, affective and cognitive measures (Haslberger et al., 2013). The two levels of correspondence in satisfaction and satisfactoriness do not only have a strong theoretical base but would also allow to explore the dynamics of adjustment over time, factoring in the individual in his or her broad context. Its operationalization will allow individuals to assess their own cross-cultural adjustment and host country people to evaluate expatriates. The correspondence idea clearly takes account of the 'requisite' need to be adjusted, which is likely to be important with regards to various organizational goals for international 
assignments (Evans et al., 2011). Thus, the impact of our proposed model goes beyond adjustment to extend to literatures such as global mobility or strategic human resource configurations (Dickmann \& Baruch, 2011).

Based on the literature and our model, we developed a number of hypotheses. We hope that these are being used to further advance the field of cross-cultural adjustment research. Using a different approach to the mainstream will lead us to deeper and new as well as exciting insights.

\section{References}

Adler, N. J. 1987. Pacific Basin Managers: A Gaijin, Not a Woman. Human Resource Management, Vol. 26, No. 2, Summer: 169-191.

Ady, J. C. 1995. Toward a differential demand model of sojourner adjustment. In R. L. Wiseman (Ed.), Intercultural communication theory (International and intercultural communication annual), Vol. XIX: 92-114. London: Sage.

Andresen, M., Al Ariss, A., \& Walther, M. (Eds.). 2012. Self-initiated expatriation - Individual, organizational, and national perspectives. London: Routledge.

Ang, S., van Dyne, L., \& Koh, C. 2006. Personality correlates of the four-factor model of cultural intelligence. Group \& Organization Management, 31(1): 100-123.

Ang, S., Van Dyne, L., Koh, C., Ng, K. Y., Templer, K. J., Tay, C., \& Chandrasekar, N. A. 2007. Cultural intelligence: Its measurement and effects on cultural judgment and decision making, cultural adaptation and task performance. Management and Organization Review, 3(3): 335-371.

Anonymous. 2009. World Values Survey 1981-2008 Official aggregate v.20090901. Madrid: World Values Survey Association (http://www.worldvaluessurvey.org), ASEP/JDS.

Anonymous. 2012. 2012 Country RepTrakTM Topline Report: Reputation Institute.

Aycan, Z. 1997. Expatriate adjustment as a multifaceted phenomenon: individual and organizational predictors. The International Journal of Human Resource Management, 8:4, August: 434-456.

Baruch, Y., Dickmann, M., Altman, Y., \& Bournois, F. 2013. Exploring International Work: Types and Dimensions of Global Careers. The International Journal of Human Resource Management, Forthcoming.

Benson, G. S. \& Pattie, M. 2009. The comparative roles of home and host supervisors in the expatriate experience. Human Resource Management, 48(1): 49-68.

Berry, J. W., Kim, U., \& Boski, P. 1988. Psychological Acculturation of Immigrants. In Y. Y. Kim \& W. B. Gudykunst (Eds.), Cross-Cultural Adaptation - Current Approaches: 62-89. Newbury Park, CA: Sage.

Bhaskar-Shrinivas, P., Harrison, D. A., Shaffer, M. A., \& Luk, D. M. 2005. Input-based and time-based models of international adjustment: Meta-analytic evidence and theoretical extensions. Academy of Management Journal, 48(2): 257-281. 
Black, J. S. \& Stephens, G. K. 1989. The influence of the spouse on American expatriate adjustment and intent to stay in Pacific Rim overseas assignments. Journal of Management, 15(4): 529-544.

Black, J. S., Mendenhall, M., \& Oddou, G. 1991. Toward a comprehensive model of international adjustment: An integration of multiple theoretical perspectives. Academy of Management Review, 16(2): 291-317.

Brammer, L. M. \& Abrego, P. J. 1981. Intervention strategies for coping with transitions. The Counseling Psychologist, 9(2): 19-36.

Breiden, O., Mohr, A. T., \& Mirza, H. R. 2006. An empirical test of a correspondence model of expatriate managers' work adjustment. The International Journal of Human Resource Management, 17(11): 1907-1925.

Brewster, C. 1993. The paradox of adjustment: UK and Swedish expatriates in Sweden and the UK. Human Resource Management Journal, 4(1): 49-62.

Brewster, C. \& Pickard, J. 1994. Evaluating Expatriate Training. International Studies of Management and Organization, Vol. 24, No. 3: 18-35.

Brewster, C. 1995. The Paradox of Expatriate Adjustment. In J. Selmer (Ed.), Expatriate Management New Ideas for International Business: 115-135. Westport, CT: Quorum Books.

Briscoe, D., Schuler, R. S., \& Claus, L. 2009. International Human Resource Management: Policies and Practices for Multinational Enterprises (3rd ed.). London: Routledge.

Caligiuri, P. M. 2000a. Selecting expatriates for personality characteristics: A moderating effect of personality on the relationship between host national contact and cross-cultural adjustment. Management International Review, 40(1): 61-80.

Caligiuri, P. M. 2000b. The Big Five personality characteristics as predictors of expatriate's desire to terminate and supervisor-rated performance. Personnel Psychology, 53: 67-88.

Chen, A. S.-Y., Lin, Y.-C., \& Sawangpattanakul, A. 2011. The relationship between cultural intelligence and performance with the mediating effect of culture shock: A case from Philippine laborers in Taiwan. International Journal of Intercultural Relations, 35(2): 246-258.

Chen, H.-F. 2010. The relationships of organizational justice, social exchange, psychological contract, and expatriate adjustment: An example of Taiwanese business expatriates. The International Journal of Human Resource Management, 21(7): 1090-1107.

Church, A. T. 1982. Sojourner Adjustment. Psychological Bulletin, 91(3): 540-572.

Cohen, E. 1977. Expatriate Communities. Current Sociology/Sociologie Contemporaine, 24, 3: 5-133.

Dawis, R. V. \& Lofquist, L. H. 1984. A psychological theory of work adjustment: an individualdifferences model and its applications. Minneapolis, MN: University of Minnesota Press.

Dickmann, M., Doherty, N., Mills, T., \& Brewster, C. 2008. Why do they go? Individual and corporate perspectives on the factors influencing the decision to accept an international assignment. International Journal of Human Resource Management, 19(4): 731-751.

Dickmann, M. \& Baruch, Y. 2011. Global Careers. New York, NY: Routledge.

Dickmann, M. 2012. Why do they come to London? Exploring the Motivations of Expatriates to Work in the British Capital. Journal of Management Development, 31(8): 783-800.

Ditchburn, G. \& Brook, E. R. 2015. Cross-cultural adjustment and fundamental interpersonal relations orientation behaviour (FIRO-B). Journal of Global Mobility, 3(4): 336-349.

Doherty, N., Dickmann, M., \& Mills, T. 2011. Exploring the motives of company-backed and selfinitiated expatriates. International Journal of Human Resource Management, 22(3): 595-611.

Dowling, P. J., Festing, M., \& Engle, A. D. 2008. International Human Resource Management: Managing people in a multinational context (5th ed.). London: Thomson Learning.

Earley, P. C. \& Ang, S. 2003. Cultural intelligence: Individual interactions across cultures. Stanford, CA: Stanford University Press. 
Earley, P. C. \& Peterson, R. S. 2004. The Elusive Cultural Chameleon: Cultural Intelligence as a New Approach to Intercultural Training for the Global Manager. Academy of Management Learning \& Education, 3(1): 100-115.

Edwards, J. R. \& Rothbard, N. P. 2000. Mechanisms linking work and family: Clarifying the relationship between work and family constructs. Academy of Management Review, 25(1): 178-199.

Edwards, J. R. 2008. Person-Environment Fit in Organizations: An Assessment of Theoretical Progress. The Academy of Management Annals, 2: 167 - 230.

Evans, M. D. R. \& Kelley, J. 2002. National pride in the developed world: Survey data from 24 nations. International Journal of Public Opinion Research, 14(3): 303-338.

Evans, P., Pucik, V., \& Björkman, I. 2011. The Global Challenge: International Human Resource Management (2nd ed.). Boston, MA: McGraw-Hill.

Fried, Y. \& Ferris, G. R. 1987. The Validity of the Job Characteristics Model: A Review and MetaAnalysis. Personnel Psychology, 40(2): 287-322.

Giacalone, R. A. \& Jurkiewicz, C. L. 2003. Toward a science of workplace spirituality. In R. A. Giacalone \& C. L. Jurkiewicz (Eds.), Handbook of workplace spirituality and organizational performance: $3-28$. Armonk, NY: M. E. Sharpe.

Greenberg, J. 2011. Behavior in Organizations (tenth ed.). Upper Saddle River, NJ: Pearson Education Prentice Hall.

Hackman, J. R. \& Oldham, G. R. 1975. Development of the Job Diagnostic Survey. Journal of Applied Psychology, 60(2): 159-170.

Hackman, J. R. \& Oldham, G. R. 1976. Motivation through the design of work: Test of a theory. Organizational Behavior \& Human Performance, 16(2): 250-279.

Hall, E. T. 1976. Beyond Culture. New York etc.: Anchor Books - Doubleday.

Harris, H., Brewster, C., \& Sparrow, P. 2004. International Human Resource Management. London: Routledge.

Harrison, D. A., Shaffer, M. A., \& Bhaskar-Shrinivas, P. 2004. Going places: Roads more and less traveled in research on expatriate experiences. In J. J. Martocchio (Ed.), Research in Personnel and Human Resource Management, Vol. 23: 199-247. Amsterdam: Elsevier Science/JAI Press.

Harrison, J. K., Chadwick, M., \& Scales, M. 1996. The relationship between cross-cultural adjustment and the personality variables of self-efficacy and self-monitoring. International Journal of Intercultural Relations, 20(2): 167-188.

Harzing, A.-W. 1995. The persistent myth of high expatriate failure rates. The International Journal of Human Resource Management, 6(2): 457-474.

Harzing, A.-W. \& Christensen, C. 2004. Expatriate failure: time to abandon the concept? Career Development International, 9(7): 616-626.

Haslberger, A. 2005. The complexities of expatriate adaptation. Human Resource Management Review, 15(2): $160-180$.

Haslberger, A. 2008. Expatriate adjustment: A more nuanced view. In M. Dickmann \& C. Brewster \& P. Sparrow (Eds.), International Human Resource Management: A European Perspective, 2nd ed.: 130-149. Abingdon: Routledge.

Haslberger, A. \& Brewster, C. 2009. Capital gains: expatriate adjustment and the psychological contract in international careers. Human Resource Management, 48(3): 379-397.

Haslberger, A. 2011. Workplace spirituality and expatriate assignments: What are the issues? Journal of Management, Spirituality and Religion, 8(1): 41-68.

Haslberger, A., Brewster, C., \& Hippler, T. 2013. The Dimensions of Expatriate Adjustment. Human Resource Management, 52(3): 333-351. 
Hechanova, R., Beehr, T. A., \& Christiansen, N. D. 2003. Antecedents and consequences of employees' adjustment to overseas assignment: A meta-analytic review. Applied Psychology, 52(2): 213-236.

Hippler, T. 2000. European assignments: international or quasi-domestic? Journal of European Industrial Training, 24(9): 491-504.

Hippler, T. 2009. Why do they go? Empirical evidence of employees' motives for seeking or accepting relocation. The International Journal of Human Resource Management, 20 (6): 1381-1401.

Hofstede, G. 2001. Culture's Consequences: Comparing Values, Behaviors, Institutions and Organizations Across Nations (2nd ed.). Thousand Oaks, CA: Sage Publications.

House, R. J., Hanges, P. J., Javidan, M., Dorfman, P. W., \& Gupta, V. (Eds.). 2004. Culture, Leadership, and Organizations: The GLOBE Study of 62 Societies. Thousand Oaks, CA: Sage.

Huang, T.-J., Chi, S.-C., \& Lawler, J. J. 2005. The relationship between expatriates' personality traits and their adjustment to international assignments. The International Journal of Human Resource Management, 16(9): 1656-1670.

Judge, T. A., Bono, J. E., \& Locke, E. A. 2000. Personality and job satisfaction: The mediating role of job characteristics. Journal of Applied Psychology, 85(2): 237-249.

Kim, K. \& Slocum, J. W., Jr. 2008. Individual differences and expatriate assignment effectiveness: The case of U.S.-based Korean expatriates. Journal of World Business, 43(1): 109-126.

Kim, Y. Y. 2001. Becoming intercultural: An integrative theory of communication and cross-cultural adaptation. Thousand Oaks, CA: Sage.

Kumar, N. \& Rose, R. C. 2008. The Effects of Personality and Cultural Intelligence on International Assignment Effectiveness: A Review. Journal of Social Sciences (15493652), 4(4): 320-328.

Langinier, H. 2012. The challenge of adjustment for expatriates coming from developing countries. EAISM Workshop on New Analyses of Expatriation, Paris, 13. - 14. December 2012, EAISM Workshop on New Analyses of Expatriation. Paris.

Lawrence, P. R. \& Nohria, N. 2002. Driven: How Human Nature Shapes Our Choices. New York, NY: Wiley.

Lazarova, M., Westman, M., \& Shaffer, M. A. 2010. Elucidating the positive side of the work-family interface on international assignments: A model of expatriate work and family performance. Academy of Management Review, 35(1): 93-117.

Lee, L.-Y. \& Sukoco, B. M. 2010. The effects of cultural intelligence on expatriate performance: The moderating effects of international experience. The International Journal of Human Resource Management, 21(7): 963-981.

Lee, T. W. \& Mitchell, T. R. 1994. An alternative approach: The unfolding model of voluntary employee turnover. Academy of Management Review, 19: 51-89.

Lewis, R. D. 2006. When Cultures Collide: Leading Across Cultures: Leading, Teamworking and Managing Across the Globe (3rd ed.). London: Nicolas Brealey Publishing.

Lips-Wiersma, M. 2002. The influence of spiritual 'meaning-making' on career behavior. Journal of Management Development, 21(7/8): 497.

Lofquist, L. H. \& Dawis, R. V. 1991. Essentials of Person-Environment-Correspondence Counseling. Minneapolis: University of Minnesota Press.

McShane, S. L. \& Von Glinow, M. A. 2010. Organizational Behavior: Emerging Realities for the Workplace Revolution (5th ed.). Boston: McGraw-Hill Irwin.

Mendenhall, M. E. \& Macomber, J. H. 1997. Rethinking the strategic management of expatriates from a nonlinear dynamics perspective. In Z. Aycan (Ed.), Expatriate management: Theory and research, Vol. 8: 41-61. Greenwich, Connecticut: JAI Press.

Miner, J. B. 2005. Organizational Behavior 1: Essential theories of motivation and leadership. Armonk, NY: M. E. Sharpe. 
Mobley, W. H. 1982. Employee turnover, causes, consequences, and control. Reading, MA: AddisonWesley.

Newman, J., Bhatt, B., \& Gutteridge, T. 1978. Determinants of expatriate effectiveness: A theoretical and empirical vacuum. Academy of Management Review, 3(3): 655-661.

Nicholson, N. 1984. A Theory of Work Role Transitions. Administrative Science Quarterly, 29, June: 172-191.

Nicholson, N. \& Imaizumi, A. 1993. The Adjustment of Japanese Expatriates to Living and Working in Britain. British Journal of Management, Vol. 4: 119-134.

Okpara, J. O. \& Kabongo, J. D. 2011. Cross-cultural training and expatriate adjustment: A study of western expatriates in Nigeria. Journal of World Business, 46(1): 22-30.

Oku, A. 2007. Intercultural Competencies required by International Managers in Managing Intercultural Teams. Cranfield University, Cranfield.

Oldham, G. R. \& Hackman, J. R. 2010. Not what it was and not what it will be: The future of job design research. Journal of Organizational Behavior, 31(2-3): 463-479.

Osland, J. S., Bird, A., Mendenhall, M., \& Osland, A. 2006. Developing global leadership capabilities and global mindset: a review. In G. K. Stahl \& I. Björkman (Eds.), Handbook of research in international human resource management: 197-222. Cheltenham: Edward Elgar.

Osman-Gani, A. M. \& Rockstuhl, T. 2009. Cross-cultural training, expatriate self-efficacy, and adjustments to overseas assignments: An empirical investigation of managers in Asia. International Journal of Intercultural Relations, 33(4): 277-290.

Patterson, A. 2013. What factors influence the decisions of employees to take up international assignments in fragile environments? , Cranfield University.

Peltokorpi, V. 2008. Cross-cultural adjustment of expatriates in Japan. The International Journal of Human Resource Management, 19(9): 1588-1606.

Peltokorpi, V. \& Froese, F. J. 2012. The impact of expatriate personality traits on cross-cultural adjustment: A study with expatriates in Japan. International Business Review, 21(4): 734-746.

Pfeffer, J. 2003. Business and the spirit. In R. A. Giacalone \& C. L. Jurkiewicz (Eds.), Handbook of workplace spirituality and organizational performance: $29-45$. Armonk, NY: M. E. Sharpe.

Popper, K. 2002. The logic of scientific discovery. London: Routledge.

Puck, J. F., Kittler, M. G., \& Wright, C. 2008. Does it really work? Re-assessing the impact of predeparture cross-cultural training on expatriate adjustment. The International Journal of Human Resource Management, 19(12): 2182-2197.

Richardson, J. \& Mallon, M. 2005. Career interrupted? The case of the self-directed expatriate. Journal of World Business, 40(4): 409-420.

Selmer, J. 2006a. Language ability and adjustment: Western expatriates in China. Thunderbird International Business Review, 48(3): 347-368.

Selmer, J. 2006b. Adjustment of business expatriates in Greater China: A strategic perspective. The International Journal of Human Resource Management, 17(12): 1994-2008.

Shaffer, M. A., Harrison, D. A., \& Gilley, K. M. 1999. Dimensions, determinants, and differences in the expatriate adjustment process. Journal of International Business Studies, 30(3): 557-581.

Shaffer, M. A., Harrison, D. A., Gregersen, H., Black, J. S., \& Ferzandi, L. A. 2006. You can take it with you: Individual differences and expatriate effectiveness. Journal of Applied Psychology, 91(1): 109-125.

Siers, B. 2007. Relationships among organisational justice perceptions, adjustment, and turnover of United States-based expatriates. Applied Psychology, 56(3): 437-459. 
Stahl, G. K., Miller, E. L., \& Tung, R. L. 2002. Toward the Boundaryless Career: A Closer Look at the Expatriate Career Concept and the Perceived Implications of an International Assignment. Journal of World Business, 37(3): 216-227.

Stahl, G. K. \& Caligiuri, P. M. 2005. The effectiveness of expatriate coping strategies: the moderating role of cultural distance, position level, and time on the international assignment. Journal of Applied Psychology, 90(4): 603-615.

Suutari, V. \& Brewster, C. 1999. International assignments across European borders: No problems? In C. J. Brewster \& H. Harris (Eds.), International Human Resource Management: Contemporary Issues in Europe: 183-202. London: Routledge.

Takeuchi, R., Tesluk, P. E., Yun, S., \& Lepak, D. P. 2005. An integrative view of international experience. The Academy of Management Journal, 48(1): 85-100.

Takeuchi, R., Shay, J. P., \& Li, J. 2008. When does decision autonomy increase expatriate managers' adjustment? An empirical test. Academy of Management Journal, 51(1): 45-60.

Taylor, S. \& Napier, N. K. 1996. Working in Japan: Lessons from Women Expatriates. Sloan Management Review, Spring: 76-84.

Templer, K. J., Tay, C., \& Chandrasekar, N. A. 2006. Motivational cultural intelligence, realistic job preview, realistic living conditions preview, and cross-cultural adjustment. Group \& Organization Management, 31(1): 154-173.

Tharenou, P. \& Caulfield, N. 2010. Will I stay or will I go? Explaining repatriation by self-initiated expatriates. Academy of Management Journal, 53(5): 1009-1028.

Thomas, D. C. \& Inkson, K. 2004. Cultural Intelligence: People Skills for Global Business. San Francisco, CA: Berret- Koehler.

Thomas, D. C. \& Lazarova, M. 2006. Expatriate adjustment and performance: a critical review. In G. K. Stahl \& I. Björkman (Eds.), Handbook of Research in International Human Resource Management: 247-264. Cheltenham: Edward Elgar.

Toh, S. M. \& DeNisi, A. S. 2003. Host country national (HCN) reactions to expatriate pay policies: a proposed model and implications. Academy of Management Review, 28(4): 606-621.

Toh, S. M. \& DeNisi, A. S. 2005. A local perspective to expatriate success. The Academy of Management Executive, 19(1): 132-146.

Toh, S. M. \& DeNisi, A. S. 2007. Host country nationals as socializing agents: a social identity approach. Journal of Organizational Behavior, 28(3): 281-301.

Trompenaars, F. \& Hampden-Turner, C. 1997. Riding the Waves of Culture: Understanding Cultural Diversity in Business. London: Nicholas Brealey Publishing.

Vaiman, V. \& Haslberger, A. (Eds.). 2013. Managing Talent of Self-initiated Expatriates: A neglected source of the global talent flow. London: Palgrave Macmillan.

Van Vianen, A. E. M., De Pater, I. E., Kristof-Brown, A. L., \& Johnson, E. C. 2004. Fitting in: Surfaceand deep-level cultural differences and expatriates' adjustment. Academy of Management Journal, 47(5): 697-709.

Vance, C. M., Vaiman, V., \& Andersen, T. 2009. The vital liaison role of host country nationals in MNC knowledge management. Human Resource Management, 48(4): 649-659.

Wang, X. 2002. Expatriate adjustment from a social network perspective: Theoretical examination and a conceptual model. International Journal of Cross Cultural Management, 2(3): 321-337.

Ward, C., Bochner, S., \& Furnham, A. 2001. The psychology of culture shock (2nd ed.). London: Routledge.

Ward, C., Leong, C.-H., \& Low, M. 2004. Personality and sojourner adjustment: An exploration of the Big Five and the cultural fit proposition. Journal of Cross-Cultural Psychology, 35(2): 137-151. 
Ward, C., Wilson, J., \& Fischer, R. 2011. Assessing the predictive validity of cultural intelligence over time. Personality and Individual Differences, 51(2): 138-142.

Waxin, M. F. 2004. Expatriates' interaction adjustment: The direct and moderator effects of culture of origin. International Journal of Intercultural Relations, 28(1): 61-79.

Figure 1: The Correspondence Model of Cross-Cultural Adjustment

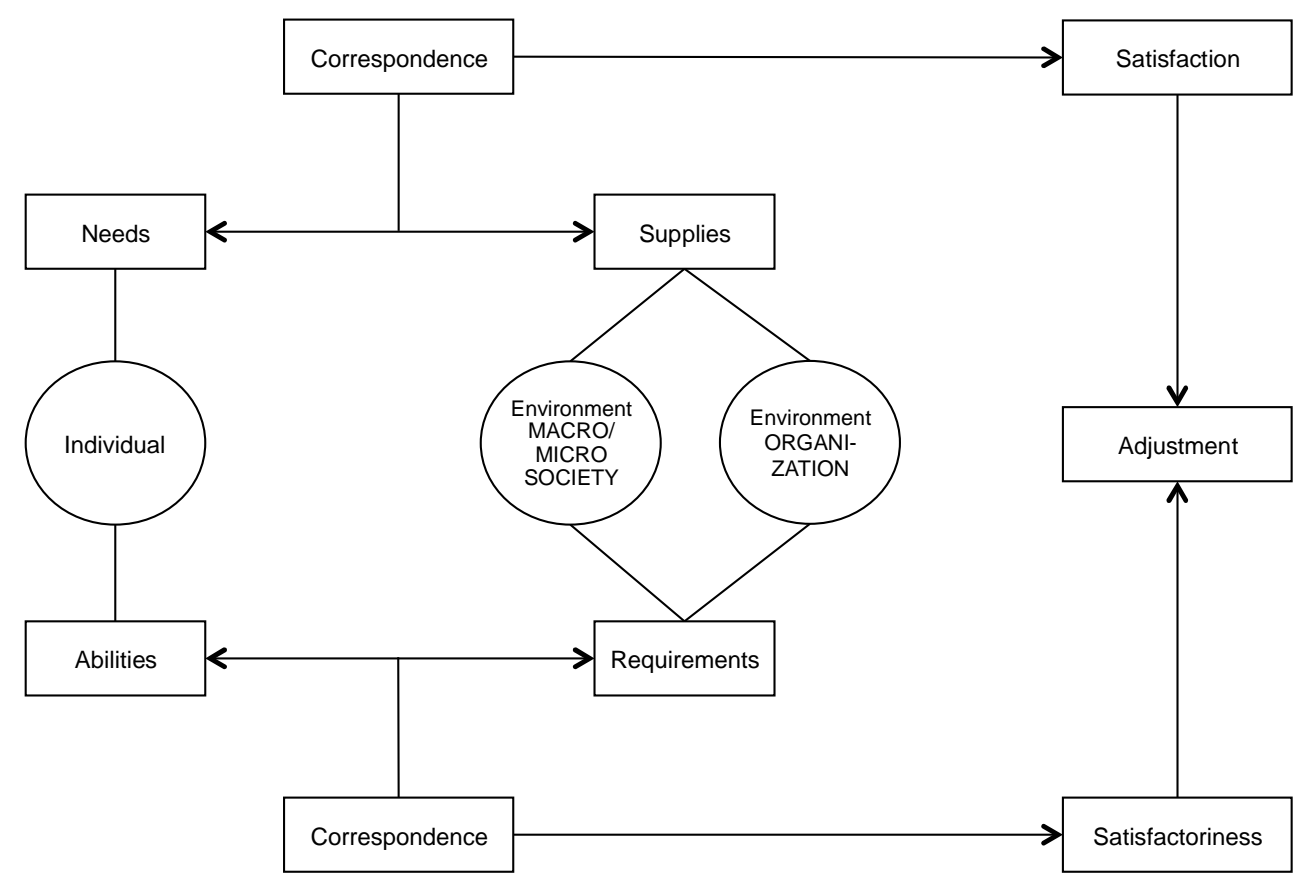


Figure 2: Key Variables of the Cross-Cultural Adjustment Model

\begin{tabular}{|c|c|c|}
\hline Individual & $\begin{array}{c}\text { CORRESPONDENCE } \\
\text { between demands and } \\
\text { resources }\end{array}$ & Environment \\
\hline Needs (demands) & $\begin{array}{l}\text { Satisfaction with } \\
\text { environment } \\
\text { (internally evaluated } \\
\text { adjustment) }\end{array}$ & Supplies (resources) \\
\hline \multirow[t]{2}{*}{$\begin{array}{l}\text { Need for feedback } \\
\text { Need for control } \\
\text { Drive to bond } \\
\text { Need to be able to pursue } \\
\text { religion }\end{array}$} & $\begin{array}{l}\text { Individual demands to be met } \\
\text { by environmental resources }\end{array}$ & $\begin{array}{l}\text { Macro/micro environment } \\
\text { Receptivity } \\
\text { Available networks \& network } \\
\text { characteristics } \\
\text { Cultural style of giving } \\
\text { feedback } \\
\text { Discretion } \\
\text { "Physical" characteristics of } \\
\text { the host location }\end{array}$ \\
\hline & $\begin{array}{l}\text { Individual demands to be met } \\
\text { by organizational resources }\end{array}$ & $\begin{array}{l}\text { Organization } \\
\text { Job design } \\
\text { Receptivity } \\
\text { Available networks \& network } \\
\text { characteristics } \\
\text { HR policies and practices }\end{array}$ \\
\hline Abilities (resources) & $\begin{array}{l}\text { Satisfactoriness of person } \\
\text { (externally evaluated } \\
\text { adjustment) }\end{array}$ & Requirements (demands) \\
\hline \multirow{2}{*}{$\begin{array}{l}\text { Personality } \\
\text { Willingness to be in host } \\
\text { location } \\
\text { Substitution capacity } \\
\text { "Cultural confidence" \& } \\
\text { identity } \\
\text { Language skills } \\
\text { Cultural intelligence }\end{array}$} & $\begin{array}{l}\text { Macro/micro environmental } \\
\text { demands to be met by } \\
\text { individual resources }\end{array}$ & $\begin{array}{l}\text { Macro/micro environment } \\
\text { Conformity pressure } \\
\text { Cultural novelty }\end{array}$ \\
\hline & $\begin{array}{l}\text { Organizational demands to be } \\
\text { met by individual resources }\end{array}$ & $\begin{array}{l}\text { Organization } \\
\text { Assignment purpose/ } \\
\text { requirement to adjust }\end{array}$ \\
\hline
\end{tabular}


Figure 3: The Correspondence Model of Cross-Cultural Adjustment (extended version)

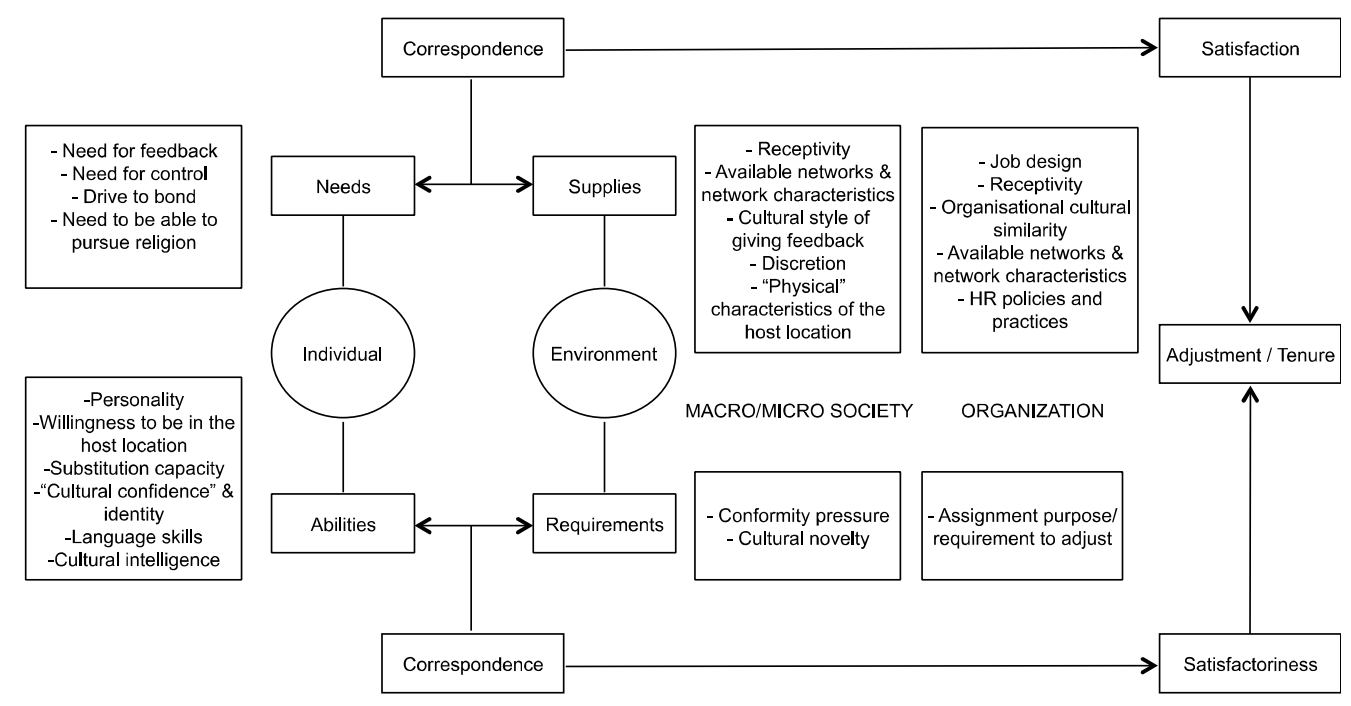




\section{Appendix 1: Implicit Assumptions of the Correspondence Model of Cross-Cultural}

\section{Adjustment}

Our discussion of the model and its variables includes some implicit assumptions, which are summarized in the following list:

- Resources are overall favorable variables that foster adjustment.

- Demands are overall challenging variables that hinder adjustment.

- Resources have to at least meet demands for positive outcomes.

- Adjustment is a process that varies over time; it is possible to take snapshots of the state of adjustment at various points in time and analyze the data so obtained to get a picture of the process.

- Some variables are antecedents to as well as outcomes of adjustment. For example, preexisting language skills upon arrival foster adjustment. But the improvement of language skills may also serve as indicator of adjustment. 


\section{Appendix 2: Additional hypotheses relating to individual needs and environmental supplies}

\section{Figure 4: Matching of individual needs and environmental supplies}

\begin{tabular}{|c|c|}
\hline Individual Needs (demands) to be met & Environmental Supplies (resources) \\
\hline \multirow{2}{*}{$\begin{array}{l}\text { Need for feedback } \\
\text { Need for control } \\
\text { Drive to bond (desire to belong, desire to } \\
\text { be accepted by hosts and interact with } \\
\text { them) } \\
\text { Need to be able to pursue religion }\end{array}$} & $\begin{array}{l}\text { Macro/micro Environment } \\
\text { Receptivity } \\
\text { Available networks \& network } \\
\text { characteristics } \\
\text { Cultural style of giving feedback } \\
\text { Discretion } \\
\text { "Physical" characteristics of the host } \\
\text { location (recreational activities, cultural } \\
\text { offers, security, climate) }\end{array}$ \\
\hline & $\begin{array}{l}\text { Organization } \\
\text { Job design (autonomy and feedback from } \\
\text { job, job complexity, role: clarity, novelty, } \\
\text { discretion, conflict) } \\
\text { Receptivity } \\
\text { Available networks \& network } \\
\text { characteristics } \\
\text { HR policies and practices }\end{array}$ \\
\hline
\end{tabular}

\section{Macro/Micro Environment}

- The expatriate's satisfaction with the environment increases to the extent that needs for general feedback, for general control, and needs related to the drive to bond are met by adequate intensiveness of non-work support systems (variables such as closeness and frequency of interaction in local and expatriate networks and with local and expatriate friends).

- The expatriate's satisfaction with the environment increases to the extent that needs for general feedback, for general control, and needs related to the drive to bond are met by adequate or better support by non-work support systems (variables such as informational, instrumental, emotional, and feedback support).

- The expatriate's satisfaction with the environment increases to the extent that the cultural style of giving feedback is aligned with the expatriate's expectation for feedback. 
- The expatriate's satisfaction with the environment increases to the extent that the discretion granted meets the expatriate's need for control.

- The expatriate's satisfaction with the environment increases to the extent that the discretion granted meets the expatriate's need to pursue religion.

- The expatriate's satisfaction with the environment increases to the extent that the characteristics of the local climate meet with the expatriate's needs and expectations.

\section{Organization}

- The expatriate's satisfaction with the organization increases to the extent that needs for general and job-related feedback and needs related to the drive to bond are met by adequate intensiveness of organizational support systems (variables such as closeness and frequency of interaction in local and expatriate networks and with local and expatriate colleagues).

- The expatriate's satisfaction with the organization increases to the extent that needs for general and job-related feedback and needs related to the drive to bond are met by adequate or better support by non-work support systems (variables such as informational, instrumental, emotional, and feedback support).

- The expatriate's satisfaction with the organization increases to the extent that needs for general and job-related feedback and needs related to the drive to bond are met or over-met by implemented state-of-the art HR policies and practices.

- The expatriate's satisfaction with the organization decreases to the extent that the expatriate's needs for feedback and for control are challenged by job complexity, role novelty, and role conflict.

- The expatriate's satisfaction with the organization increases to the extent that needs for general and job-related feedback and needs related to the drive to bond are met by the size (in terms of sheer numbers) of organizational support systems. 